\title{
THE RESULTS OF PARTIAL GASTRECTOMY
}

\section{A Review of the Follow-up of 180 cases of Partial Gastrectomy for Peptic Ulcer}

\author{
By J. Cosbie Ross, Ch.M., F.R.C.S.(Eng.) \\ Surgeon to the Royal Southern Hospital, Liverpool \\ and \\ ANThoNy Walsh, M.A., M.B., F.R.C.S.(Ireland) \\ Resident Surgical Officer, Royal Southern Hospital, Liverpool
}

During the 12 year period ending in March 1947, I80 patients suffering from peptic ulcer were submitted to partial gastrectomy by one of us (J.C.R.), at Smithdown Road City Hospital, Liverpool. It is proposed here to give an account of the follow-up of these patients. Our object has been to present a simple factual account of the experience derived from a personal series. To avoid any possible tendency to biased judgment the follow-up was carried out independently by A.W.

This series does not include any in which the operation was performed for the relief of malignant disease, nor any in which subsequent evidence revealed that an ulcer, thought to be benign, was in fact carcinomatous. In all but a few of the early cases the Polya technique was used, removing the entire stomach except for a small sac at the fundus ; the removal included the pylorus and as much as feasible of the first part of the duodenum in every case. We lay great stress on the extensive character of the resection and in many cases a mere fringe of the fundus was preserved for the purpose of the anastomosis. This necessitates ligation of many of the vasa brevia. In some of the earlier cases the Finsterer type of operation was used, but this was soon abandoned in favour of a complete removal of the pylorus. Similarly, the Hoffmeister valve was fashioned in a few instances but was soon discarded as being timeconsuming and of doubtful value. In all but the most recent cases the anastomosis between the gastric sac and the jejunum was ante-colic. In some the technique was altered to provide a retrocolic, no-loop anastomosis. Experiment has shown that the daily intramuscular injection of $30 \mathrm{mgm}$. of histamine-base in beeswax in laboratory animals causes a torrent of acid secretion which breaks down the capacity of tissue in contact with the acid to defend itself against digestion. In a series of gastrectomized dogs the histamine-beeswax technique always produced a stomal ulcer when a long afferent loop was used, but never with a short loop (Wangensteen, 1944).

Wells and Brewer (1948) have recently expressed a preference for the antecolic jejunal loop. They state that 'the retrocolic manoeuvre introduces the risk of some obstruction where the mesocolon embraces the jejunum.' This danger is avoided by suturing the edges of the gap in the mesocolon to the stomach above the anastomosis. If, however, the transverse mesocolon was short or adherent or difficulties arose as a result of a high resection, the antecolic method was selected as the additional time and manipulation did not seem justifiable. The main difficulty of gastrectomy lies in the closure of the duodenum in the presence of an adherent duodenal ulcer fixed to the posterior abdominal wall or to the pancreas. This difficulty may. be so great that it is advisable to conclude the gastrectomy by dividing the pyloric antrum, leaving the pylorus and the first part of the duodenum to be removed at a subsequent operation. The method of Yudin (1946) does not strengthen the weak point of the closure, i.e. the posterior wall of the duodenum, and we have found the manoeuvre advised by Nissen (1945) more helpful in this regard.

An attempt was made to trace all the patients, our aim being to interview and examine all who could be located. A few patients who could not attend the hospital were asked to fill in a simple questionnaire. No patient was seen less than six months, and only iI less than 12 months after discharge from hospital. Of the I80, II were known to be dead. Of the remaining 169, I07 were found and interviewed, leaving 62 cases (37 per cent.) untraced. Of the 107 traced, II were discarded as being too recent (less than six months after operation). The loss to follow-up of 
37 per cent. is hardly surprising when one remembers that all the patients came from an area which was extensively 'blitzed' and that some of the addresses given by the patients on entering the hospital were seamen's lodging houses.

So far we have referred to 'peptic' ulcer. In the series 95 were gastric, 80 duodenal and in five cases both gastric and duodenal ulcers were present. It was, however, found that with one or two minor exceptions to be noted later, it appeared to make little difference to the results whether the ulcer had been duodenal or gastric or both.

The principal indications for operation in this series were :-

I. Failure to respond to adequate medical treatment in uncomplicated cases.

2. The lesser curve gastric ulcer (unless very small).

3. Persistence of symptoms after recovery from perforation.

4. A history of two or more perforations.

5. Pyloric stenosis in the presence of active ulceration.

6. Repeated haemorrhage.

7. The pyloric ulcer.

8. The possible ulcer-cancer.

TABLE I

Duration of symptoms before operation in the cases traced

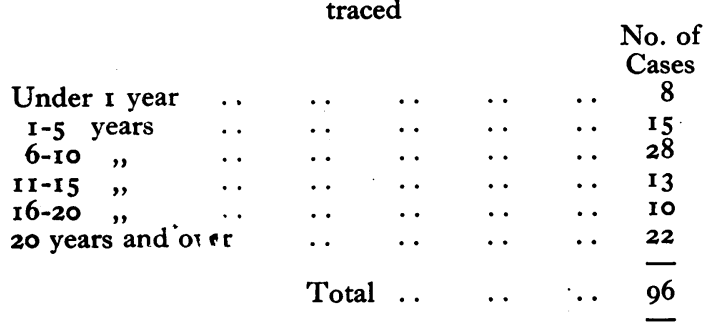

There were three points of special interest :-

I. Patients with a history of one year and under all had large ulcers. Of the eight in this group seven were symptomless until the onset of a complication such as haemorrhage. It is worth recalling at this point that the duration of symptoms may be much less than the actual life of the ulcer, as indicated by those cases of perforation which at operation show an obviously chronic lesion although there had been no symptoms prior to the acute catastrophe (Cosbie Ross, 1940). It is noteworthy that the ' silent ulcer' is most commonly a large gastric ulcer situated on the lesser curvature or posterior wall of the stomach, and is found in thin, elderly patients. At the other end of the scale is the younger, more $?$ robust individual suffering from a small $\stackrel{\varnothing}{\complement}$ duodenal ulcer with clamant symptoms.

2. The group with symptoms present for six to ten years included all those with a history of a previous perforation.

3. The duration of symptoms does not appear $\frac{\overline{\bar{p}}}{\vec{D}}$ to influence the uniformly satisfactory $\stackrel{\Phi}{\varrho}$ results.

Operative mortality. Eight patients died as a $\vec{\circ}$ direct result of the operation, a mortality rate of $\rightarrow$ 4.5 per cent. Considering the poor general con- $\vec{\omega}$ dition of many of the subjects, whose ages ranged $\frac{\Omega}{8}$ from 25 to 69 years, and who were typical of the $\frac{0}{3}$ practice of a municipal hospital (including no private patients), this figure is not unsatisfactory. or Further, this series dates back to 1935 , prior to $N_{\infty}$ the considerable recent advances in anaesthesia + and preceding the introduction of valuable ad- 8 ditional forms of therapy. We may confidently expect that in the future the mortality will be re- $\triangle$ duced. Table 2 gives the details of the fatal $\vec{c}$ cases.

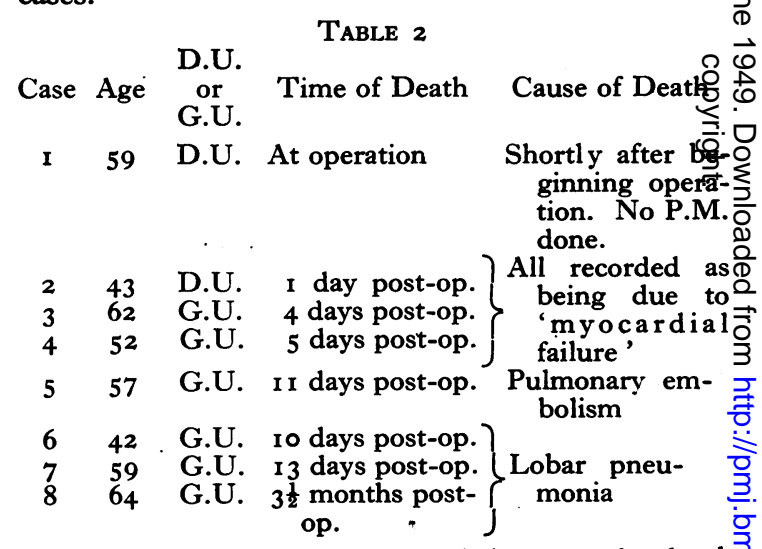

In Case 7 operation was carried out under local anaesthesia. The patient collapsed while the splanchnic? area was being infiltrated, but recovered sufficiently to allow the operation to be continued.

An observation of importance in this table is that all the deaths were primarily due to disease of the cardiovascular or respiratory systems, and N therefore it is to these systems that we must look in our efforts to reduce the operative risk. NoO deaths were due to purely local factors at the operation site, despite the occurrence in one in stance of a duodenal fistula. At the same time, it should be noted that two cases of duodenal $\mathbb{D}$

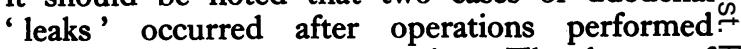
subsequent to the present series. The danger of ${ }^{T}$ this complication has already been emphasized.

Three patients of the series are known to have $\stackrel{\rho}{\stackrel{\rho}{\circ}}$ died since discharge from hospital. One woman, $\stackrel{\mathbb{2}}{0}$ 
aged 45 , was murdered 18 months after operation for duodenal ulcer. One man of 42 years died 17 months after the operation with a carcinoma of the lower end of the oesophagus ; either this was not present or it was overlooked at the time of the operation. The third case must be considered in more detail. This was a man who, in 1925 at the age of 40, perforated a duodenal ulcer; he had a second perforation in I934. On each occasion the perforation was treated by simple suture. In September, 1940, a Finsterer-type partial gastrectomy was performed for chronic duodenal ulcer. After this he appeared to do well, but was readmitted in November 1941 with general peritonitis and died shortly after operation for a perforated anastomotic ulcer. Looking back, we consider that this death from perforated stomal ulcer (incidentally the only known stomal ulcer in the series), might have been avoided if a total gastrectomy had been done rather than the partial -operation. Recently, evidence has been accumulating which suggests that in such cases with a history of repeated perforation it is not only justifiable, but advisable to perform a total or almost a total gastrectomy.

In following up these cases a primary concern was to find out the patient's own estimate of the value of the operation. In the present age of mass statistics and scientific analysis there is an unfortunate tendency to regard the patient merely as a unit in a table of figures and to disregard his or her personal reaction to treatment. In the eager pursuit of pathology we are inclined now and then to forget our primary obligation, which is to relieve our patient as far as possible of his disease or discomfort. It was Osler who said ' Every medical student should remember that his end is not to be made a chemist or even a physiologist or an anatomist, but to learn to recognize and treat disease, to become a practical physician.'

In Table 3 we have grouped the patients as ' extremely satisfied,' ' satisfied,' ' only moderately satisfied,' and ' dissatisfied.'

TABLe 3

$$
\text { G.U. D.U. } \begin{gathered}
\text { G.U. } \\
\& \\
\text { D.U. }
\end{gathered}
$$

$\begin{array}{lllllll}\text { Extremely satisfied } & \ldots & \ldots & 40 & 36 & 2\end{array}$

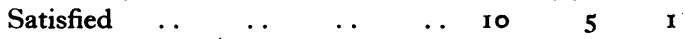

Only moderately satisfied $\quad \ldots \quad 0 \quad 2 \quad 20$

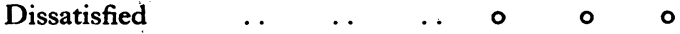

The two patients who were 'only moderately satisfied' were both seriously ill with conditions unconnected with the peptic ulcer, one had advanced phthisis and the other syringomyelia. All except the two mentioned above were almost embarrassingly grateful.
No patient in this series had kept to any special diet for more than six months after operation. All were taking normal meals, although seven reported that they had to avoid greasy foods as these tended to make them vomit.

Table 4 shows the incidence of residual symptoms in the 96 patients at the time of the follow-up examination.

\section{TABLE 4}

D.U. G.U. $\underset{\&}{\text { D.U. Total }}$

Complete freedom from all

$\begin{array}{lrrrrrr}\text { symptoms } & \ldots & \ldots & 34 & 34 & 2 & 70 \\ \text { ccasional mild symptoms } & 4 & 16 & \text { I } & \text { 21 } \\ \text { requent pain } & \ldots & \ldots & 4 & 0 & 0 . & 4 \\ \text { Persistent vomit ing } & \ldots & \text { I } & 0 & 0 & \text { I }\end{array}$

Of the 96 cases 73 per cent. were thus completely free of all symptoms and will not be considered further. The 2 I patients with occasional mild symptoms included the seven previously mentioned who tended to vomit after greasy foods, ten who felt discomfort after heavy meals and four who had occasional attacks of ' heartburn.' The single patient with persistent vomiting was suffering from advanced phthisis with cavitation in both lungs. The four patients who still hado frequent pain all said that they were much improved by the operation, although still prone to dyspeptic attacks. It is possibly of some? significance that the patient complaining of occasional vomiting had had a gastric ulcer removed, while pain was the more common residual symptom in those whose ulcer had been duodenal.

Of the ten who felt discomfort after heavy meals, eight stated that this took the form of a dragging sensation in the left hypochondrium and the left side. We have not been able to find any reference in the literature to this symptom after gastrectomy. The sensation appears to be located just in front of the splenic area and it is difficult to provide a satisfactory explanation. As the anastomotic line lies high under the left costal margin, it may possibly be due to traction on the parietal peritoneum by adhesions.

It was noted that the result in cases of duodenal ulcer did not depend always on the removal of the actual ulcer. Of the four individuals with recurrent pain, three had had a duodenal ulcer removed. Of the 34 who were completely symptomfree, several had not had the ulcer removed owing to technical difficulties, while in three of the four with occasional mild symptoms the ulcer had been excised together with the greater part of the stomach.

Many of the patients felt a marked diminution of strength since the gastrectomy. This was noted in ten of the 43 patients with a duodenal ulcer and 
in 13 of the 50 in whom a gastric lesion had been found. This symptom does not appear to have been commented on by previous writers, probably because it has not been specifically sought. In the series it came to light only as the result of direct questioning. Twenty of the 23 cases complaining of diminished strength had had to seek less arduous employment, but in no instance was the loss of strength sufficient to cause serious inconvenience; 94 patients had been regularly at work and were leading normal lives.

\section{Post-operative Anaemia}

No patient in the series showed any marked degree of anaemia, with the exception of the man with phthisis and the patient with syringomyelia who both had a gross microcytic anaemia.

A full blood investigation was carried out in 27 patients, but no case of macrocytic anaemia occurred in the series. The blood examinations were grouped into those performed within five months of the operation and those between five and 12 months after the gastrectomy. In the first, or earlier group, the average haemoglobin was 90.1 per cent., while in the second (later) group the figure had risen to 93.5 per cent.

This observation supports the widely accepted view that the secondary anaemia is a temporary feature and tends to be corrected in the course of time. It was noted that the lowest figures in either group ( 65 per cent. $\mathrm{Hb}$ in group one and 47 per cent. $\mathrm{Hb}$ in group two), were found in female patients.

\section{TABLE 5}

Number of blood examinations . . $\quad \ldots \quad \ldots \quad \ldots 27$

(a) Within 5 months of operation $\quad \ldots \quad$.. 17 Average haemoglobin percentage $\quad \ldots .90 .1$

(b) Between 5 and 12 months after operation 10 Average haemoglobin percentage $\quad \ldots \quad 93.5$

\section{Abdominal Scar}

In 87 of the cases the operative incision had been midline and in the remaining nine a right or left paramedian one. It was disappointing to find that there was a high incidence of incisional hernia, varying in degree from simple divarication of the recti muscles to one case with a protrusion the size of an orange. The incidence of postoperative herniae was eight in 50 gastric and three in 43 duodenal cases. Other authors have reported a similarly high incidence of hernia in stomach operations performed through a vertical incision.

Finally, no case of 'dumping syndrome' occurred (Irvine, 1948; Adlersberg, 1947).

\section{Conclusion}

This report is a further confirmation of the $\frac{3}{\mathbb{Q}}$ opinion, expressed by many writers in recent years, $\frac{\varrho}{c}$ that in properly performed gastrectomy we have a reliable cure for one of the commoner ills of our $\overrightarrow{\overrightarrow{\vec{S}}}$ time. No longer need sufferers from peptic ulcer $\overrightarrow{0}$ linger through years of misery, their gloomy faces and uncertain tempers adding yet another burden $\overline{\bar{c}}$

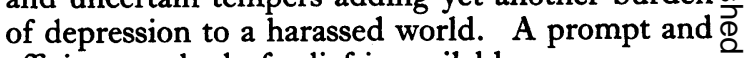
efficient method of relief is available.

\section{Summary}

A report is presented of the follow-up of $180 \overrightarrow{\vec{\omega}}$ patients who underwent partial gastrectomy for $\stackrel{\Omega}{\circ}$ peptic ulcer at one hospital in the 12 years prior $\frac{0}{7}$ to March, 1947.

I. The operative mortality was 4.5 per cent. in three further patients are known to have $\stackrel{\infty}{+}$ died since leaving hospital.

2. Ninety-six .were interviewed, and tables are

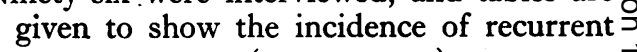
symptoms ; 70 (73 per cent.) were com- $\vec{c}$ pletely symptom-free; 21 (22 per cent.) $\frac{\check{\digamma}}{5}$ showed occasional mild symptoms; five ${ }^{\circledR}$ (5 per cent.) had more severe symptoms.

3. Generally speaking, the greater the time thet had elapsed since the operation, the better the result. Secondary anaemia and postprandial distension and discomfort tend to disappear in the course of time.

4. Two unforeseen sequelae are reported. Eight $\stackrel{\overparen{D}}{\rightarrow}$ cases complained of a dragging sensation under the left costal margin and in the left side. In 23 patients a marked, though not incapacitating diminution of strength wasreported.

5. No case of macrocytic anaemia was found in the present series.

6. A high incidence of hernia in the vertical incision was noted.

7. No cases of 'dumping syndrome' were found.

\section{BIBLIOGRAPHY}

ADLERSBERG, D., and HAMMERSCHLAG, E. (1947), Surgery, 21, p. 720 .

GORDON TAYLOR, G. (1946), Brit. F. Surg., 33, 336.

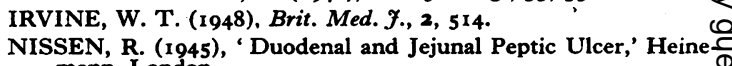
mann, London.

ROSS, J. COSBIE (r 940), Brit. Med. F., 2, 665.

WANGENSTEEN, O. H. (1944), Minnesota Med., 27, 714.

WELLS, C. A., and BREWER, A. C. (1948), Brit. F. Surg., 35, 364, 